\title{
Sobre a entrevista de Paul Feyerabend a Rüdiger Safranski em 1993
}

Profa. Dra.

Cristina de Amorim Machado Universidade Estadual de Maringá

cristina_machado@yahoo.com

Para citar este artigo: MACHADO, Cristina de Amorim. obre a entrevista de Paul Feyerabend a Rüdiger Safranski em 1993. Em Construção. ano. 1, No. 1, 2017, pp. 165-178. DOI:10.12957/ emconstrucao.2017.28132
Como assim, nunca estiveram em Alfa do Centauro? Ora bolas, humanidade, fica só a quatro anos-luz daqui! Desculpem, mas, se vocês não se dão ao trabalho de se interessar pelas questões locais, o problema é de vocês.

A ciência conseguiu algumas coisas fantásticas, não vou negar, mas acho mais importante estar feliz do que estar certo.

- Olhe - disse Frankie -, essa história de idealismo, de dignidade da pesquisa pura, da busca pela verdade em todas as suas formas, está tudo muito bem, mas chega uma hora que você começa a desconfiar que, se existe uma verdade realmente verdadeira, é o fato de que toda a infinidade multidimensional do Universo é, com certeza quase absoluta, governada por loucos varridos.

Douglas Adams, O guia do mochileiro das galáxias, p. 34, 140, 145

Este texto apresenta trechos de uma das últimas entrevistas de Paul Feyerabend (1924-1994), filósofo da ciência austríaco que lecionou em Berkeley e Zurique, publicou diversos livros e artigos, e colecionou alguns afetos e muitos desafetos no meio acadêmico-científico. Aos trechos da entrevista, acrescentei comentários e tracei relações com algumas ideias veiculadas em seus principais livros.

É importante registrar que este é mais um fruto do projeto realizado em 2014 pelos grupos de pesquisa GP de Science Studies da UEM e Estudos Sociais e Conceituais de Ciência, Tecnologia e Sociedade (UERJ) em homenagem aos 90 anos de nascimento de Feyerabend. Ele consistiu na transcrição do áudio da entrevista e posterior tradução (alemão-português) por Adriano Steffler, seguida da legendagem do vídeo por 
Carlos Puig. O produto dessa empreitada se encontra em nosso canal no Youtube (https://www.youtube.com/ watch? $=w M a z V l i m y P c)$ desde então e já teve mais de quatro mil visualizações (janeiro de 2017). Ademais, ao longo desse mesmo ano realizamos a Oficina Contra o Médodo na UEM, atividade em que comparamos as duas edições brasileiras (traduções da primeira e da terceira edições) do livro Contra o método, de Feyerabend; e no fim do ano fizemos uma Jornada Feyerabend na UERJ, na qual apresentamos os resultados dessa oficina e assistimos pela primeira vez à entrevista já legendada.

A entrevista com Feyerabend foi realizada num café em Roma ao pé da Catedral de São Pedro, cerca de um ano antes de sua morte. Seu entrevistador era Rüdiger Safranski, filósofo alemão estudioso de Nietzsche, Heidegger e do romantismo alemão. O clima era descontraído, e a conversa nos permite ver e ouvir um Feyerabend de gestos apaixonados e palavras rápidas, o que se encaixa perfeitamente na imagem que seus leitores produzem dele. O reconhecimento também se dá pela criticidade e pelo humani(tari)smo que atravessam tudo o que ele fala, como se pode ver já no título que foi atribuído à entrevista: Ó céus, o que é um ser humano?

Todas as citações são da referida entrevista, exceto quando especificadas outras fontes, cujas referências completas se encontram no fim do texto, mas que serão assim identificadas: CM - Contra o método ( $3^{\mathrm{a}}$. edição); CSL - Ciência em uma sociedade livre; AR - Adeus à razão; DC - Diálogos sobre o conhecimento; CA - Conquista da abundância; MT - Matando o tempo; TC - The tyranny of Science [A tirania da ciência]; e WK - Wissenshaft als Kunst [Ciência como arte].

\section{A entrevista}

Inicialmente, Feyerabend fala do que Safranski chamou de centralismo, mas que talvez se possa entender melhor em termos feyerabendianos como a "admirável monotonia nova" (AR, p. 325) ou o monismo de grandes unidades de pensamento ou ideologias hegemônicas, que, de maneira geral, nem afetam as vidas das pessoas comuns, são "apenas uma fantasia nas mentes de algumas pessoas". Daí para a relativização do valor das luzes da razão universal, que afastariam para sempre a imaturidade, e a relação entre ciência e fé foi um pulo. Afirmando que a imaturidade faz parte da vida, Feyerabend diz que o ser humano precisa de mais amabilidade e menos iluminismo, e que a crença na ciência médica, por exemplo, é equivalente à crença religiosa combatida pelos iluministas, e que talvez aí esteja o xis da questão, a necessidade de confiar, a segurança:

a criança pequena precisa da segurança de seus pais, a pessoa adulta precisa da segurança de seus amigos. [...] A gente precisa desse tipo de segurança, e se a segurança está relacionada com o querido Deus, por quê não? Essa é uma decisão pessoal de cada ser humano. Mas [há] uma campanha iluminista de considerar apenas o conhecimento [...] - Qual tipo de conhecimento? - Ah, o das partículas elementares! - de que me servem as partículas elementares quando quero me enforcar de desespero? Para isso não há nada no Iluminismo! Onde há algo no Iluminismo para um ser humano desesperado?

É nesse momento que Feyerabend começa a tratar de um assunto que já aparece em outros escritos seus (por exemplo, TC, p. 126; CM, p. 356-7; CSL, p. 150-1): a contraposição entre o local e familiar ao universal e abstrato, que se desdobra, como já se vê no subtítulo de CA, em "uma história da abstração versus a riqueza do ser".

Todo médico e padre da aldeia conhece todas as pesoas em sua aldeia mais ou menos bem, e pode oferecer um aconselhamento melhor do que qualquer conhecimento filosófico. [...] Não há vidas gerais. [...] Em um círculo de amigos, pelo contrário, eu posso dizer: pois então, veja, o que você está fazendo é uma grande idiotice, sobretudo porque um amigo pode se defender. Quando, de forma abstrata na tela da televisão, uma celebridade ilustre insiste com um pobre desorientado sobre a sabedoria das palavras dessa pessoa esperta, ele não pode, definitivamente, se defender: um amigo pode dizer, essa é a coisa mais idiota que eu já ouvi, e eles dizem isso, não é verdade? 
Ele ainda leva essa questão da familiaridade ao paroxismo, contando que uma vez, diante da sua imagem no espelho, por um instante não se reconheceu e passou a se perguntar: "Ó céus, o que é um ser humano?"

Nessa passagem, ele também aponta para duas questões interligadas que são recorrentes em seus escritos (por exemplo, CSL, p. 108-10; 127-8; 218-9; CM, p. 67-8; 333-6; 352-3), que são a crítica da "medicina científica" e da "cultura do especialista", ambas derivadas do estatuto privilegiado das ciências em nossas sociedades contemporâneas. Para Feyerabend, as ciências são tradições, e todas as tradições, numa sociedade livre, deveriam ter o mesmo valor. Quando uma tradição se sobrepõe às outras, tornando-se hegemônica - e foi isso o que aconteceu com essa abstração chamada ciência -, não há liberdade, e sim tirania. Daí o título que foi atribuído em inglês ao seu último livro (póstumo), que é uma coletânea de conferências realizadas em Trento em 1992 - The tyranny of Science.

Em seguida, o entrevistador pede para Feyerabend falar sobre a verdade, e ele começa assim a sua resposta: "Veja bem, o que é a verdade? Diga-me! Eu entendo perfeitamente quando alguém me diz: meu querido amigo, ontem você realmente mentiu para mim, isso faz todo sentido para mim, eu disse algo e as coisas não eram bem assim [...]." Logo depois, ele passa ao problema da imposição da verdade: "a pessoa que fala da verdade sempre introduz nela a sua filosofia privada e, por isso, diz: vocês precisam fazer desse jeito ou de outro porque isto é a verdade"; para finalmente chegar às diversas ciências, citando alguns exemplos com seus variados procedimentos e resultados, como se o ser ou a natureza respondesse "às vezes um pouco mais amigavelmente, às vezes não". A eficiência, no entanto, dá a impressão de unidade, mas esses resultados eficientes não são necessariamente bons. Aqui Feyerabend toca na questão da desunidade da ciência, que é uma de suas bandeiras e que acabou sendo o título do segundo capítulo de TC.

Ao mencionar o exemplo do Projeto Genoma Humano, Feyerabend desdobra a questão num sentido ético-político, lembrando da resposta de um biólogo molecular à questão do seu custo de milhões de dólares, se não seria melhor doar esse dinheiro para as pessoas que estão jogadas pelas ruas, que não têm uma residência e são pobres, a fim de salvá-las? A resposta foi mais ou menos assim: "O que vocês não entendem é que essas pessoas estão jogadas por aí devido a causas genéticas, e se encontrarmos o genoma humano, então encontraremos o motivo de eles serem sem-teto, então nós poderemos mudar isso." Para Feyerabend, esse determinismo é uma "ideia louca", mas que interessa, por motivos diferentes, a alguns sociólogos e biólogos. Por isso, para ele, a questão da responsabilidade é muito importante porque "repentinamente as coisas se alteram de uma forma tal que um observador de fora diria - e um como eu - minha nossa, como é miserável essa história toda. Por isso, é necessário cuidado redobrado com todas essas questões gerais."

Safranski se interessa por essa discussão bioética e pergunta a Feyerabend sobre a desumanidade de certa forma de pesquisar que implica o "uso desenfreado de animais para a pesquisa de processos orgânicos, etc., ou seja, não há já no desejo de saber das ciências modernas um problema, não há nelas um problema ético, com relação ao qual nós devemos reagir?"

Para responder a essa questão, Feyerabend reconta, como já fez em seus livros (por exemplo, em CSL, p. 28; CA, p. 38-41; DC, p. 81-83), um pouco da gênese grega dessa tradição científica, racional e objetiva, que desencanta o mundo, a abundância do ser, restringindo-o a abstrações. Do pluralismo de deuses à separação corpo-alma e ao monoteísmo-monismo teórico, foram excluídos do domínio do conhecimento científico, por exemplo, a metafísica, os sonhos e as artes. E o pior, isso foi imposto a outras culturas, como se fosse o único e verdadeiro conhecimento, solapando suas tradições. Para Feyerabend, numa sociedade livre, isso deveria ser uma opção: "nós temos algo que pode ajudar vocês, que eles considerem isso como uma ajuda externa e não como algo que tem a ver com o ser da natureza das coisas."

Sobre os experimentos com animais, Feyerabend diz queé muito complicado tomar decisões gerais em termos de pesquisas médicas e nos convida a pensar sobre pesquisas que podem salvar vidas humanas: "[...] Eu naturalmente me decidiria pela pessoa querida, o que mais? Por isso, para mim é tão difícil fazer julgamentos gerais [...].”

Quando perguntado sobre a qual razão ele dá adeus em AR, Feyerabend começa respondendo assim: "Daquela razão que pode ser usada pelas pessoas para reprimir ou suprimir outras pessoas [...], a fim de 
proibir o discurso a outras pessoas ou declarar o discurso como sem sentido, etc. A esse tipo de razão eu digo adeus, com ela eu não tenho nada a ver." Ele segue lembrando a razão kantiana e o seu imperativo categórico, especialmente no caso da mentira (cf. também TC, p. 114-117):

\begin{abstract}
há muitas circunstâncias em que é simplesmente humano mentir, e muitas outras circunstâncias em que é indecoroso e em que também é muito ruim e muito mau mentir. Assim, esse tipo de razão que edifica uma estrutura a que todos os seres humanos estão subjugados e diz: nós somos os administradores dessa estrutura e se vocês agora não seguirem exatamente no caminho dessa estrutura, então acontecerá algo terrível com vocês. Pois bem, isso é simplesmente tirania.
\end{abstract}

Como já dito nos seus livros, especialmente em AR, Feyerabend trata a razão como uma prática (ver também, por exemplo, CM, p. 289-308; CSL, p. 23-41) que, como qualquer prática, constitui uma tradição. Historicamente, no entanto, essa tradição racional e objetiva das ciências tornou-se hegemônica no mundo junto com a cultura do homem branco ocidental, de maneira geral à força, mas também por meio de uma propaganda extremamente eficaz. É por isso que, na sequência, ele atravessa outro ponto que aparece em todos os seus escritos (por exemplo, CM, p. 34; TC, p. 125) e que tem relação direta com a nossa disponibilidade para essa propaganda: a educação. O conhecimento vivo, rico e dinâmico é estabilizado, simplificado e pasteurizado, pronto para o consumo:

\begin{abstract}
Eu diria que uma questão [...] que os jovens deveriam aprender é manter um pouco de bom senso perante essas supostas descobertas e conhecimentos, etc. Veja bem, [...] essas pessoas dirão: nós pesquisamos, nós descobrimos importantes verdades com grandes dificuldades, nós oferecemos a vocês essas verdades, aceitem-nas, comam da árvore do conhecimento. Vocês receberão os seus vermes corrompidos, provavelmente, mas pensem nisso [...], o estômago de vocês não digere tudo, e vocês não percebem que têm um verme corrompido, não percebem que o nariz de vocês fica mais comprido, que os olhos de vocês começam a ficar vesgos, e assim por diante. Sejam cuidadosos, sejam cuidadosos! Eu diria isso [...], mas também não assim no sentido do Iluminismo, sempre ser crítico [...].
\end{abstract}

Para Feyerabend, a educação deveria ser crítica e abrangente, uma atividade entre amigos, e não a lavagem cerebral que se encontra nas escolas e universidades, cuja única preocupação é formar especialistas nas tradições científicas: "um amigo pode se defender, um aluno não pode se defender tão bem, sobretudo quando há provas". Ele reconhece a dificuldade de se implementar uma educação realmente livre - e até mesmo uma sociedade livre em que todas as tradições tenham os mesmos direitos e possam interagir -, mas isso não o impede de colocar em xeque a suposta objetividade da educação, que se baseia numa suposta objetividade inerente ao conhecimento científico que, como vimos, não se sustenta.

Ele fecha esse ponto questionando certas pesquisas que fazem correlações bizarras, lembrando-nos da sua posição em relação à autonomia da ciência. Para Feyerabend, a ciência deve ser submetida ao escrutínio público. Apesar de não se aprofundar nisso nessa entrevista, em CSL (p. 124), CM (p. 335-6) e TC (p. 89-90), só para citar três exemplos, ele trata dessa questão junto com o problema dos especialistas científicos. Talvez isso evitasse, como diz ele:

correlações entre coisas que realmente não combinam: compara-se, por exemplo, o teor de açúcar no sangue com quantas separações essa pessoa tem [...], então há, sim, uma leve correlação positiva, por isso verifique o seu teor de açúcar no sangue e assim por diante. Ou então, teste o seu casamento, talvez seja o contrário, não é?

Perguntado se invejava os gregos e seus deuses - provavelmente pela recorrência em seus escritos de referências à filosofia grega -, Feyerabend diz que invejava: 
o tempo em que o ar era muito mais puro e em que se podia respirá-lo com prazer, e em que as florestas estavam povoadas por seres vivos ou por algo semidivino, semiterreno, isso era um contínuo, havia não somente os deuses, havia também os semideuses, isso era um contínuo.

Ele lembra que essas ideias também se encontram em Goethe, e que não se tratava de respeito à natureza, como dizemos hoje, porque os humanos se viam como parte da natureza que, por sua vez, era parte do divino. Para Feyerabend, eram tempos mais ricos, e ainda havia o atomismo, a matemática e o teatro. Em relação ao teatro grego, ele destaca o seu caráter democrático e pedagógico: "participava todo o povo, não apenas algumas pessoas ricas ou algumas pessoas com um gosto extravagante, e ele era estabelecido de tal modo que as pessoas podiam entendê-lo". Lembrando que era uma democracia diferente da que concebemos hoje, com a maioria da população (escravos e mulheres) sem direito a voto, Feyerabend enfatiza que "aqueles que tinham direito a voto, os cidadãos plenos, eles se pronunciavam". Ele ainda cita a Oréstia como exemplo de "que emoção, divindade, razão, tudo trabalhava junto, e não assim separado".

Como se vê numa rápida passada de olhos nas epígrafes de CM ou na sua autobiografia (MT, p. 36, 6670, 76-7, 81-2, 90-3), as artes em geral, mas o teatro e o canto em particular, eram uma paixão de Feyerabend. Em seu livro WK, ele se dedica a essa relação entre ciência e arte, que já aparece frequentemente em seus escritos, como em AR (p. 173-193), TC (p. 25-6) e CM (p. 233-256), só para citar alguns exemplos.

Feyerabend reconhece que na antiguidade grega "as mulheres não desempenhavam um papel tão bom assim, embora existissem poetisas", mas havia uma maior interação entre os seres vivos, e "isso era melhor para eles, e não é sentimentalismo, é riqueza maior". Para fechar esse assunto, ele recomenda que se olhe para o passado de outro modo:

E então também construir cidades que caibam na natureza, quero dizer, há belas construções aqui, quando se olham as plantas mais antigas, e também Florença, as coisas mais antigas, isso é muito bonito, isso excede a natureza e, obviamente, muitas coisas foram perdidas. E também apender algo com o Iluminismo, mas sem destruir aquelas coisas que se sabia antes, mas lidar com elas em outro espírito.

Mudando completamente de assunto, Safranski pergunta a Feyerabend sobre Wittgenstein, o que lhe dá a oportunidade de revisitar essa parte da sua biografia, já contada em CM (p. 347-9) e MT (p. 83-4), e que diz respeito ao período do Círculo Kraft, "uma versão estudantil do velho Círculo de Viena" (MT, p. 83), do qual Viktor Kraft fizera parte:

Então eu fundei um grupo para nós, junto com um professor, Viktor Kraft, que não fazia boas preleções, mas era uma boa pessoa, [...] foi aposentado durante o período nazista, se tornou bibliotecário, [...] e com ele fundamos um grupo de estudantes em que ele, como se diz, era o coordenador acadêmico, e assim ele nos arranjou umas salas na universidade, onde podíamos nos encontrar. E então, em sequência, convidamos várias pessoas, dentre elas também Elizabeth Anscombe, uma das discípulas de Wittgenstein, e ela nos introduziu ao estilo de Wittgenstein, como uma língua é aprendida, etc. Quando ela foi embora, a maioria disse: "Que tipo de psicologia infantil primitiva é essa?" [...] E eu disse isso a Anscombe, que falou: "Oh, Wittgenstein está em Viena! Ele deveria falar para vocês!"

Feyerabend segue narrando o "evento Wittgenstein" no Círculo Kraft, sem agregar muito ao que já havia escrito em MT e CM sobre a estranheza da atitude inicial à alegria final de Wittgenstein depois da visita ao círculo:

Pois bem, [...] eu já tinha ouvido boatos de que ele era uma pessoa um pouco esquisita "como chego até ele [...]?". Primeiro eu fui à casa dele; [...] havia uma entrada, havia már- 
mores escuros, tudo muito escuro, e de algum lugar veio uma voz: "Quem é o senhor?", era o porteiro, era ele. Eu disse: "Meu nome é fulano de tal, e eu gostaria de falar com Wittgenstein". Uma longa pausa, longa pausa. A voz volta e diz: "O senhor Wittgenstein sabe de você, mas ele não pode te ajudar". Pois bem, eu fui embora e disse a Anscombe: "Wittgenstein sabe de mim, mas não pode me ajudar". E então Anscombe disse: "Agora você vai escrever uma carta para ele!”, e, para ser mais precisa, não uma carta submissa, mas uma informal: "Nós temos um grupo aqui, nós falamos sobre enunciados básicos [...], eu ouvi dizer que você está na cidade e que também disse algo a respeito disso. Você não poderia nos visitar?" [...] Pois bem, o dia chegou, e todos estavam reunidos, e nada do Wittgenstein, e assim simplesmente começamos, pois para eles, para todos os outros, Wittgenstein era apenas um filósofo idiota. [...] Ele entrou bem no meio da discussão, ele estava na porta, e a primeira impressão do rosto dele era como uma maçã enrugada, visto que tinha muitas rugas, liso, mas muitas rugas. Naquela época ele já tinha câncer, era muito pouco tempo antes de sua morte [...]. Ele entrou e se assentou, eu estava discursando, eu sempre fazia a introdução e então eu falava muito. E eu ainda me lembro dele levantando a mão: "Parem, assim não dá!” E ele começou a falar com muitos exemplos, e então a discussão começou, não me lembro mais direito dela, e ele foi bastante atacado, e parece que lá ele se sentiu bem, pois normalmente ele estava rodeado por pessoas que "oh, Wittgenstein, Wittgenstein!", e elas não davam importância alguma àquela pessoa e aquela discussão era sem importância, e eu disse: pois é, até que ele nem é tão ruim, e assim por diante, e foi isso.

Para finalizar a entrevista, Safranski chama Feyerabend de filósofo e pede para que ele descreva a sua atividade. Feyerabend reage como em seu livro DC (p. 66), onde disse que não era filósofo, nunca havia sido e que não tinha "nenhum desejo de ser afligido por esse gênero de condição", e fala um pouquinho da sua atividade docente:

Eu não sou filósofo! Veja bem, no momento estou aposentado, sou um aposentado; e essa é uma vida muito agradável. Antes, de acordo com o meu título, eu era professor de filosofia, da área de filosofia da ciência. Bom, nunca levei muito a sério esse título. Nas minhas preleções eu lia o que me dava satisfação e, às vezes, aquilo que eu queria estudar. A melhor forma de estudar alguma coisa é fazer uma preleção sobre ela. A mim vinham pessoas que estavam interessadas em ciências, e eu sempre tive interesse pelas ciências, e por isso eu falava um pouco sobre a história das ciências.

Com destaque para Platão e Aristóteles, que já são figuras recorrentes na obra feyerabendiana, como se vê, por exemplo, em DC (p. 11-63), CA (p. 289-296) e CSL (p. 68-82):

Subitamente, Platão me fascinou muito, não porque ele era um filósofo, mas porque era uma pessoa interessante e porque viveu em uma época bastante interessante. Assim, eu fiz preleções sobre Platão. Depois toda uma preleção sobre a física de Aristóteles, que é muito difícil e porque são anotações de preleções, e não um manuscrito pronto para publicação. Nela havia muitas ideias fantásticas. Por que eu critiquei essas ideias? Porque eu sempre ouvi, minha nossa, esse velho e impossível Aristóteles que inibiu as ciências modernas por tanto tempo. Ele foi um homem sensato, muito mais sensato do que muitos cientistas modernos. Isso me interessou e, por isso, eu o estudei e fiz apresentações sobre ele em todo lugar em que estive.

E uma crítica a Husserl e a todos os filósofos que não saem de seus gabinetes:

O que sabe Husserl? - eu li sua obra uma vez, às vezes eu dou uma espiada nela: 'Nós, como filósofos, temos a tarefa de melhorar a humanidade, os porta-estandartes da hu- 
manidade'. O que esse indivíduo sabe da humanidade? Ele fica sentado em seu escritório, estuda de um lugar-comum a outro, o que ele sabe de agricultores peruanos? [...]. Essas pessoas são loucas!

\section{Considerações finais}

Evidentemente Feyerabend não tratou de todas as suas ideias nessa curta entrevista. Para isso, é importante ler sua obra, seus comentadores e contemporâneos. Só assim podemos ter uma imagem um pouco mais definida de sua concepção das ciências como tradições que, por sua vez, são práticas humanas e, como qualquer atividade humana, não se traduzem em harmonia, ordem, unidade e afins, trata-se de conflito constante, interação e desunidade. Isso porque a natureza é abundante, complexa e plural, e assim é a abordagem humana e criativa das ciências. Qualquer tentativa de unificar ou regular essas práticas - de conquistar essa abundância - é tirânica, dogmática e desumanizante, uma imposição da teoria, de abstrações artificiais supostamente universais - como o método da ciência moderna ou a razão objetiva - sobre a experiência prática humana, que é local.

Essa produção monista de "admiráveis monotonias novas” tem uma genealogia e, ao puxar o fio da meada, o pluralista Feyerabend chega a Xenófanes e Parmênides. Quer seja o deus único do primeiro ou o ser-é do segundo, encontramos aqui abstrações, criaturas desconectadas da vida humana cotidiana, ao contrário dos deuses homéricos, que viviam entre os homens. E é justamente esse ser apartado da humanidade que está nas fundações da tradição científica racional e objetiva. Para agravar ainda mais essa desumanização dos deuses, essa tradição desumanizou a natureza (separação entre natureza e cultura) e, finalmente, os próprios humanos ( separação entre objetividade e subjetividade), produzindo a perda das especificidades individuais típicas das generalizações. Com isso, os humanos perdem suas individualidades e se transformam em objetos. O mito da ciência una, monística e universal se impõe como tirania da abstração e se contrapõe à experiência subjetiva que dá sentido à vida. O perigo é evidente, por isso o constante alerta de Feyerabend para as relações entre ciência e sociedade, e sobretudo para as questões éticas envolvidas na atividade científica.

\section{Referências bibliográficas}

FEYERABEND, Paul. Entrevista concedida a Rüdiger Safranski em Roma, 1993. Tradução de Adriano Steffler. Vídeo (legendado por Carlos Puig) disponível em: https://www.youtube.com/watch?v=wMazVlimyPc.

. Wissenschaft als kunst. Frankfurt am Main: Editora Suhrkamp, 2013 [1984].

. The tyranny of science. Edição e introdução de Eric Oberheim. Cambridge: Polity Press, 2011.

. A ciência em uma sociedade livre. Tradução de Vera Joscelyne. São Paulo: Unesp, 2011 [1978].

. Adeus à razão. Tradução de Vera Joscelyne. São Paulo: Unesp, 2010 [1987].

. Contra o método. 3a . edição. Tradução de Cezar Augusto Mortari. São Paulo: Editora Unesp, 2007 [1993].

. A conquista da abundância. Tradução de Cecilia Prada e Marcelo Rouanet. São Leopoldo/RS: Editora Unisinos, 2006 [1999].

Diálogos sobre o conhecimento. Tradução de Gita K. Guinsburg. São Paulo: Editora Perspectiva, 2001.

Matando o tempo: uma autobiografia. Tradução de Raul Fiker. São Paulo: Editora UNESP, 1996. 